\title{
CHARACTERIZATION AND EQUALIZATION OF THE AC RESPONSES OF THE CORRECTOR MAGNETS FOR THE APS LOCAL ORBIT FEEDBACK SYSTEM
}

\author{
C. Doose and S. H. Kim \\ Advanced Photon Sour. Argonne National Labu atory \\ 9700 South Cass Avenue, A gonne, Illinois 60439
}

\section{Abstract}

Local feedback for the APS storage ring uses local bumps to control the position and angle of the $z_{i}$ osit beam through each $\mathrm{x}$-ray source point. Induced eddy currents in the aluminum vacuum chanber dominate the AC characteristics of the correc or nagnetic fields. Small differences in the geometr es at each magnet location change the eddy current effects a $d$ result in bump closure errors wh: ch must be reduced in order to minimize the coupli; $g \mathrm{~b}$ ' veen each of the many local loops and the global contrc' loop. By a combination of flux-damping coils, flux-shielding copper sheets, and a set of steel laminations for end-fix clamping, the differences of the eddy current effects between two corrector magnets were reduced from $0.18 \mathrm{Gm} / \mathrm{A}$ to $0.035 \mathrm{Gm} / \mathrm{A}$ in the frequency span of $0.1-100 \mathrm{~Hz}$.

\section{INTRODUCTION}

Around the 40 sectors of the Advanced Photon Source (APS) storage ring [1], 360 if beam position monitors (BPMs) and 318 horizontal/vertical corrector magnets have been installed for both local and global orbit correction feedback systems [2]. The local feedback systems control the position and angle of the positron beam locally at the source points for the $x$-ray beams. The corrector magnets, which correct local orbit bumps up to $0.1 \mathrm{mrad}$ from $\mathrm{DC}$ to $30 \mathrm{~Hz}$, induce eddy current in the relatively thick aluminum vacuum chamber and other metallic components. The effects of the eddy current in the magnet laminations, which have a thickness of 0.64 $\mathrm{mm}$, are negligibly small [3].

The local feedback system uses four correctors, two on each side of an insertion device. The sections of the vacuum chamber near the two corrector magnets, $\mathrm{BH}$ and $\mathrm{BH} 2$ on a girder upstream or downstream of the insertion device, are machined differently for the vacuum port and flange couplings, which changes the eddy current effects. Therefore, when the two magnets are energized with certain ratios of the magnet current, the differences in the eddy current effects result in bump closure errors as a function of frequency. The closure errors must be reduced in order to minimize coupling between each of the many local loops and the global control loop.

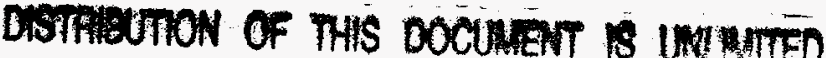

\section{AC RESPONSE MEASUREMENTS}

The two corrector magiets $\mathrm{BH} 1$ and $\mathrm{BH} 2$ were measured on a storage ring sparc girder assembly that has all the eddy-current-related components, including the alv uum vacuum chamber. The iwo magnets were coni. ted in series to a bipolar pou $\mathrm{r}$ supply/amplifier, Kepco _. P 20-20M [4], in order io have a commoncurrent phase reference for the measurement. The power supply was driven in a current-controlled mode by a random frequency signal from a Hewlett Packard $35670 \mathrm{~A}$ four-channel analyzer [4]. The signals from two "printed circuit" coils located in each magnet gap inside the vacuum chamber were processed using the analyzer to obtain the response of the integrated magnetic field strength to the magnet current in the frequency domain.

Figure 1 shows the magnitudes of the vertical field strength $\mathrm{B} \ell(\omega) /(\omega)$ of magnet $\mathrm{BH} 2$, and that of the difference between $\mathrm{BH} 1$ and $\mathrm{BH} 2$. The frequency span for the measurements was $0.1-100 \mathrm{~Hz}$ with a resolution

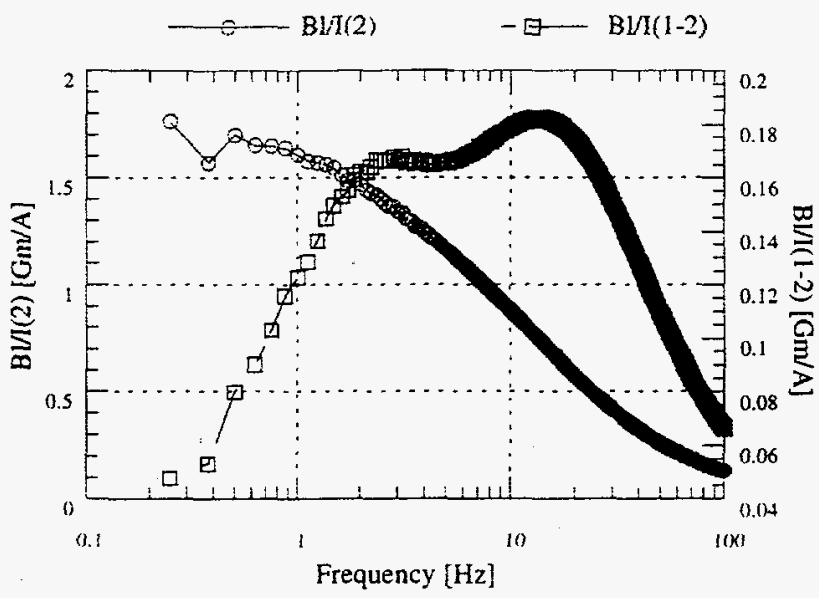

Figure 1: Magnitudes of the vertical field strength per current $B \ell(\omega) /(\omega)$. $B \ell \Lambda(2)$ for magnet $\mathrm{BH} 2$ and $\mathrm{B} \ell \Pi(1-2)$ for the difference between magnets $\mathrm{BH} 1$ and $\mathrm{BH} 2$.

of $0.125 \mathrm{~Hz}$, and rms magnet current for the frequency span was $10 \mathrm{~A}$. The corresponding spectra of the phase shift for the field strength are plotted in Fig. 2. Magnet BH1, located closer to the stainless steel flange of the vacuum chamber at the end section of the girder, has 5-

The submitted manuscript has been created by the University of Chicago as Operator of Argonne National Laboratory ("Argonne”) under Contract No. W-31-109-ENG-38 with the U.S. Deparment of Energy. The U.S. Government retains for itself, and others acting on its behalf, a paid-up, nonexclusive, irtevocable worldwide license in said article to reproduce, prepare derivative works. distribute copies to the public, and perform publicly and display publicly, by or on behalf of the Government- 


\section{DISCLAIMER}

This report was prepared as an account of work sponsored by an agency of the United States Government. Neither the United States Government nor any agency thereof, nor any of their employees, make any warranty, express or implied, or assumes any legal liability or responsibility for the accuracy, completeness, or usefulness of any information, apparatus, product, or process disclased, or represents that its use would not infringe privately owned rights. Reference herein to any specific commercial product, process, or service by trade name, trademark, manufacturer, or otherwise does not necessarily constitute or imply its endorsement, recommendation, or favoring by the United States Government or any agency thereof. The views and opinions of authors expressed herein do not necessarily state or reflect those of the United States Government or any agency thereof. 


\section{DISCLAMIER}

Portions of this docament may be illegible in electronic image products. Imsges are produced from the best available original docement 


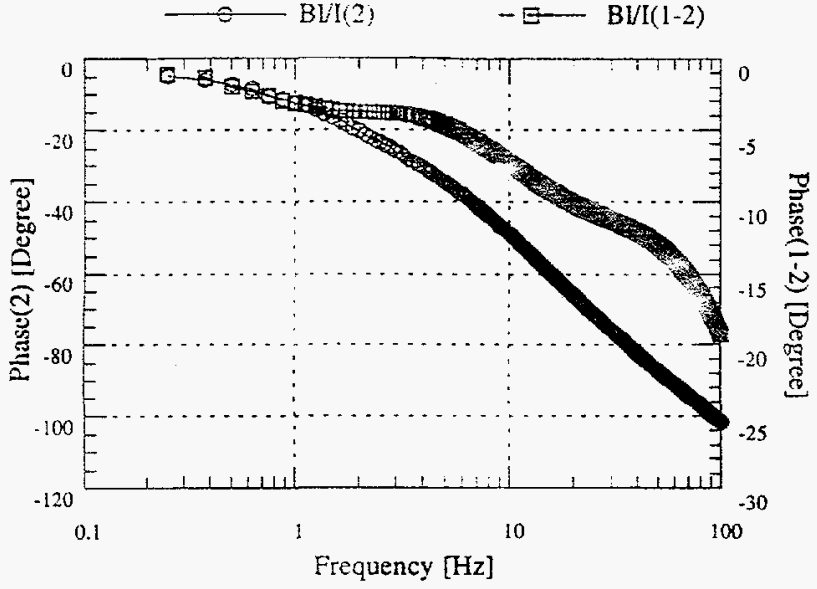

Figure 2: Phase delays of the vertical field strength per current $B \ell(\omega) /(\omega)$. Phase(2) for magnet $\mathrm{BH} 2$ and $\mathrm{Phase}(1-2)$ for the difference between magnets $\mathrm{BH} 1$ and $\mathrm{BH} 2$.

$20 \%$ less attenuation and phase shift of the magnetic field compared to those of magnet $\mathrm{BH} 2$.

\section{EQUALIZATION OF THE AC RESPONSE}

Three methods of compensation were used to equalize the response of $\mathrm{BH} 1$ on the $\mathrm{AC}$ magnet current to that of $\mathrm{BH} 2$. The first method installed a one-turn flux-damping coil (4/0 cable) around the "back leg" of the flux-return core near the midplane of the magnet in Fig. 3. (The upper half of the two-dimensional cross section for the steel lamination, magnet coils, and vacuum chamber is shown in Fig. 3. The flux lines in the figure are for a DC current.) The damping coil was most effective in changing the response in the frequency band of 4-15 Hz.

The second method shielded and damped the magnetic flux using 1-mm-thick copper sheets as shown in the left two poles in Fig. 3. The copper sheets were cut approximately $7 \mathrm{~cm} \times 2.5 \mathrm{~cm}$ to fit on the pole tips of the magnet. The copper sheets were effective in changing the response above $15 \mathrm{~Hz}$.

The third method used a set of U-shaped steel laminations (approximate cross section of $1.2 \mathrm{~cm} \times 1$ $\mathrm{cm}$ ) hung on top of the magnet core across the 7-cm-long magnet near the center pole. This method was effective in the overall frequency band. The laminations diverted a small fraction of the flux from the air gap of the magnet similar to a flux shunt or end-flux clamping scheme.

Using a combination of these three methods for magnet BHl significantly reduced the differences in the magnitude and phase delay between the two magnets. The results of the combination are plotted in Fig. 4. The difference in phase delay is now less than $1^{\circ}$, and the difference in magnitude is now less than $0.035 \mathrm{Gm} / \mathrm{A}$, a fivefold reduction compared to $0.18 \mathrm{Gm} / \mathrm{A}$ before the compensation.

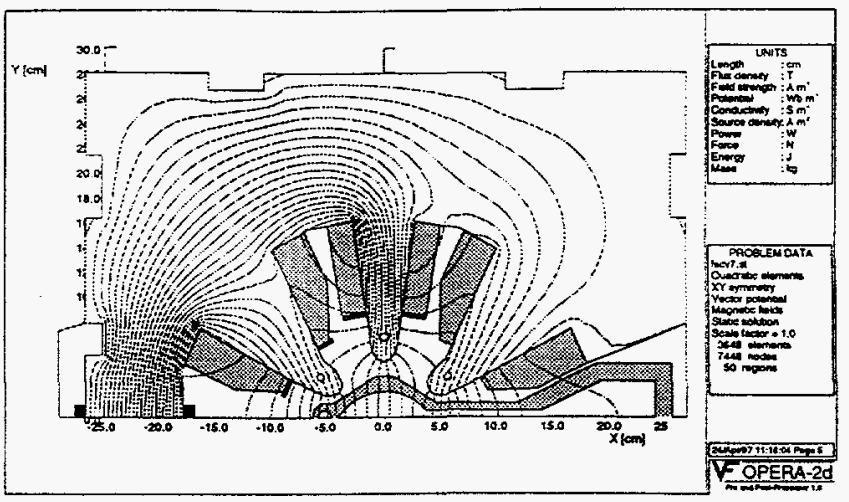

Figure 3: Upper half of the 2-D cross section of the magnet laminations, magnet coils, and vacuum chamber along with flux lines for $D C$ current. The flux-damping coil and copper sheets for the flux shielding on two magnet poles are shown

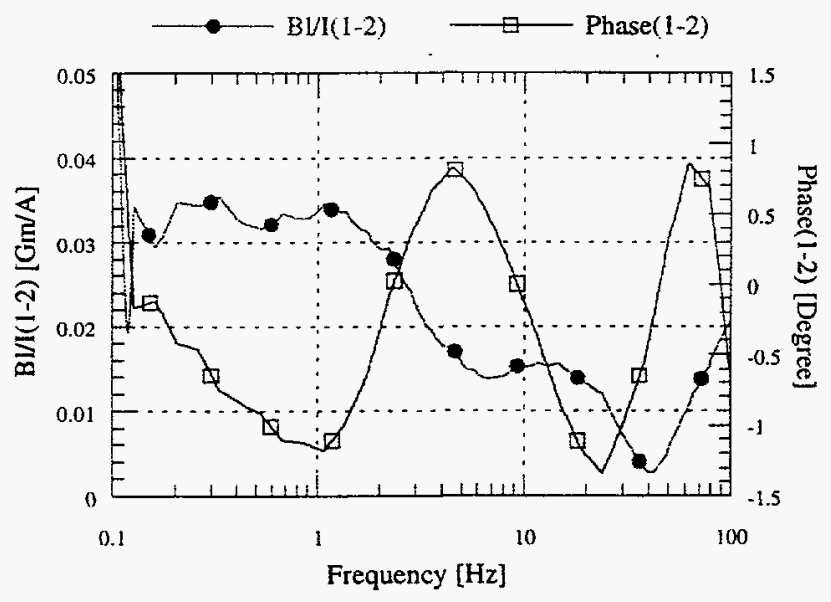

Figure 4: The differences of the magnitude, $B \ell /(1-2)$, and phase delay, Phase(1-2), of the $\mathrm{AC}$ responses between magnets $\mathrm{BH} 1$ and $\mathrm{BH} 2$ with the three methods of flux compensation.

\section{CONCLUSION}

To minimize the local orbit closure errors, AC response differences in the vertical field strengths of two corrector magnets were reduced from $0.18 \mathrm{Gm} / \mathrm{A}$ to $0.035 \mathrm{Gm} / \mathrm{A}$ in the frequency span of $0.1-100 \mathrm{~Hz}$. This was achieved by three methods of flux compensation: damping, shielding, and shunting. Similar compensation methods for the correction of horizontal field have to be tested. The methods need to be simplified for easy installation in the storage ring. 


\section{ACKNOWLEDGMENTS}

The authors gratefully acknowledge J. Galayda for his encouragement and suggestions for the work. This work was supported by the U.S. Department of Energy, Office Basic Energy Sciences, under Contract No. W-31-109ENG-38.

\section{REFERENCES}

[1] J. N. Galayda, "The Advanced Photon Source," Proc. of the 1995 PAC, IEEE 95CH35843, 4 (1996).

[2] J. Carwardine et al., "Commissioning of the APS Real-Time Orbit Feedback System," these proceedings.

[3] Y. Chung and J. Galayda, "Effect of Eddy Current in the Laminations on the Magnet Field," LS Note 200, ANL, 1992.

[4] An explicit reference to a particular product does not imply that other vendors might not be able to supply equivalent products. 